\title{
Uma nova espécie do gênero Cyphonia Laporte (Hemiptera, Auchenorrhyncha, Membracidae)
}

\author{
Gabriel Simões de Andrade
}

Centro de Ciências Biológicas e da Saúde, Universidade Estadual do Oeste do Paraná. Rua Universitária 2069, Caixa Postal 711, 85819-110 Cascavel, Paraná, Brasil. E-mail: gsa@certto.com.br

\begin{abstract}
A new species of the genus Cyphonia Laporte (Hemiptera, Auchenorrhyncha, Membracidae). Cyphonia tumefata sp. nov., from Barigüi, Paraná State, Brazil, is described and illustrated. KEY WORDS. Ceresini, Membracoidea, Smiliinae, taxonomy.
\end{abstract}

RESUMO. Cyphonia tumefata sp. nov. de Barigüi, Estado do Paraná, Brasil, é descrita e ilustrada. PALAVRAS CHAVE. Ceresini, Membracoidea, Smiliinae, taxonomia.

O gênero Cyphonia Laporte, 1832 foi revisto por SAKAKIBARA $(1968,1972)$. Kopp \& YONKE $(1979)$ elevaram os dois subgêneros, Cyphonia s. str. e Eucyphonia Sakakibara, à categoria de gênero. No catálogo de McKameY (1998) são citadas 26 espécies como válidas. BARReira \& SAKAKIbARA (2001) descreveram mais duas novas espécies para o gênero. Neste artigo é acrescentada mais uma nova espécie, procedente de região de mata Atlântica do sul do Brasil.

\section{Cyphonia tumefata sp. nov.}

\section{Figs 1-2}

Tipo e localidade-tipo. Holótipo fêmea de "Barigui P[a]r[aná]./8.IV.[1]962/R. Lange leg.", "R. Lange/No 3771", depositado na coleção de Entomologia "Pe. J.S. Moure" do Departamento de Zoologia da Universidade Federal do Paraná, Curitiba, Paraná, Brasil.

Medidas em milímetros. Holótipo fêmea. Largura da cabeça: 1,60; comprimento da cabeça: 0,80; distância entre os ângulos umerais: 1,67; distância entre os ápices dos processos supra-umerais: 1,60; distância entre os ápices dos ramos do processo pronotal mediano: 0,40; distância entre os ápices dos processos pronotais laterais: 1,34 ; comprimento do pronoto: 4,35; comprimento total: 5,22 .

Descrição. Holótipo fêmea. Coloração geral amarelada; pontos em algumas granulações dos processos supra-umerais e cúculos setíferos dos processos pronotais posteriores, acastanhados; ápices dos processos supra-umerais acastanhados, ápices dos processos pronotais posteriores negros. Região ventral do corpo amarelada, com as coxas posteriores maculadas de castanho enegrecido. Tégminas hialinas, veias amareladas e escurecidas apicalmente a partir da segunda célula apical.

Cabeça esculturada, depressa junto a margem superior. Sutura coronal bem marcada, atingindo a base do frontoclípeo. Ocelos situados em protuberâncias entre a sutura coronal e os olhos, na altura da linha imaginária que passa pelo centro dos olhos, e mais próximos dos olhos que entre si. Espaços ocelooculares deprimidos e corrugados. Lóbulos supra-antenais corrugados, com as margens arredondadas. Frontoclípeo sublosângico em vista frontal, fortemente intumescido, com a metade distal dirigida para trás.

Pronoto com granulações verrucosas no metopídio, processos supra-umerais, espaço entre os processos supra-umerais e base dos processos pronotais posteriores. Processos supraumerais curtos e cônicos, com os ápices dirigidos para os lados e para trás. Processo mediano com os ramos divergentes entre si, inclinados para trás e com os ápices situados em nível superior a altura dos ápices dos processos supra-umerais e da base dos processos pronotais posteriores. Ângulos látero-posteriores do pronoto não projetados, largamente obtusos. Processos pronotais posteriores não globulares, base comum esférica e intumescida. Processos laterais engrossados na metade basal e afilados na metade distal, ligeiramente encurvados para cima na metade distal. Processo mediano gradualmente afilado para o ápice desde a base, com curvatura acompanhando o bordo interno das tégminas, e com o ápice atingindo a altura da base da terceira célula apical das tégminas.

Os demais caracteres como na caracterização do gênero. Macho. Desconhecido.

Difere das demais espécies notadamente pelo aspecto fortemente intumescido do frontoclípeo.

\section{AGRADECIMENTOS}

Ao Prof. Dr. Vladimir Pavan Margarido (Universidade Estadual do Oeste do Paraná), pela confecção dos originais das fotografias.

\section{REFERÊNCIAS BIBLIOGRÁFICAS}

Barreira, R.L. \& A.M. SaKakibara. 2001. Duas espécies novas de Cyphonia Laporte da região central do Brasil. Revista Brasileira de Zoologia, Curitiba, 18 (1): 239-244.

Revista Brasileira de Zoologia 21 (1): 13-14, março 2004 


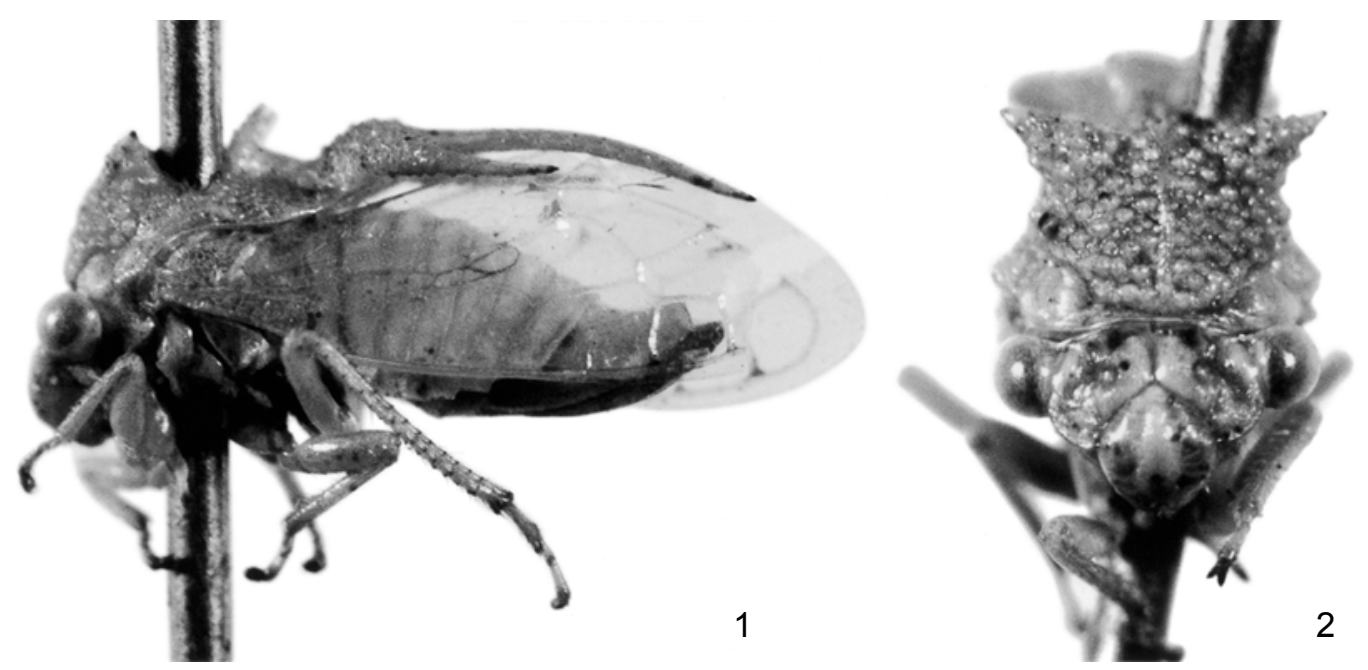

Figuras 1-2. Cyphonia tumefata sp. nov., holótipo fêmea: (1) vista lateral esquerda; (2) vista frontal.

Kopp, D.D. \& T.R. Yonke. 1979. A taxonomic review of the tribe Ceresini (Homoptera: Membracidae). Miscellaneous Publications of the Entomological Society of America, College Park, 11 (2): 1-97.

McKameY, S.H. 1998. Taxonomic catalogue of the Membracoidea (Exclusive of Leafhoppers) - Second supplement to Fascicle 1 - Membracidae of the General Catalogue of the Hemiptera. Memoirs of the American Entomological Institute,
Gainesville, 60: 1-377.

SaKakibara, A.M. 1968. Revisão das espécies do gênero Cyphonia Laporte (Homoptera, Membracidae, Smiliinae). Studia Entomologica, Petrópolis, 11 (1-4): 417-476.

. 1972. Revisão do gênero Cyphonia Laporte "addenda et corrigenda" (Homoptera, Membracidae). Revista Brasileira de Biologia, Rio de Janeiro, 32 (1): 117126.

Recebido em 02.VII.2003; aceito em 12.XI.2003. 